\title{
Estimativa da população em unidades de conservação na Amazônia Legal brasileira - uma aplicação de grades regulares a partir da Contagem 2007
}

\author{
Álvaro de Oliveira D’Antona* \\ Maria do Carmo Dias Bueno* \\ Ricardo de Sampaio Dagnino"
}

Neste artigo é testado um método para aumentar a resolução de dados censitários e apresentá-los agregados em uma grade regular. A metodologia empregada é composta pela agregação dos domicílios representados por suas coordenadas geográficas obtidas pela Contagem da População do Instituto Brasileiro de Geografia e Estatística (IBGE) de 2007 e pela desagregação dos dados por setor censitário utilizando proporcionalidade de área. Os dados assim gerados foram usados para estimar a população residente em 114 unidades de conservação da Amazônia Legal brasileira, criadas até 2006, de modo a testar a metodologia em unidades territoriais que não seguem os limites político-administrativos, nem aqueles das unidades territoriais de coleta utilizados pelo IBGE. Esta metodologia também contribui para os estudos de população em áreas protegidas, dada a escassez de estimativas do volume da população em unidades de conservação. Os resultados mostraram uma população nas unidades selecionadas de 325.398 habitantes, sendo 297.693 em unidades de Uso Sustentável e 27.705 em unidades de Proteção Integral; no entorno estimou-se uma população de 1.020.237 habitantes. Apesar de limitações inerentes ao uso da Contagem 2007, a agregação de dados em grades revela-se como uma metodologia bastante promissora, tendo em vista os avanços no emprego das geotecnologias por parte do IBGE desde então. A grade minimiza problemas observados no uso de unidades administrativas ou de coleta para a espacialização dos dados censitários e apresenta-se como uma abordagem com grande potencial de aplicação na Demografia e em outras áreas do saber.

Palavras-chave: Grades regulares. Amazônia Legal brasileira. Unidades de conservação. Estimativa da população.

\footnotetext{
* Faculdade de Ciências Aplicadas (FCA) da Universidade Estadual de Campinas (Unicamp), Campinas-SP, Brasil (alvaro. dantona@fca.unicamp.br).

** Programa de Pós-Graduação em Demografia do Instituto de Filosofia e Ciências Humanas (IFCH) da Unicamp, CampinasSP, Brasil (maria.bueno@ibge.gov.br).

${ }^{* \star *}$ Programa de Pós-Graduação em Demografia do Instituto de Filosofia e Ciências Humanas (IFCH) da Unicamp, CampinasSP, Brasil (ricardosdag@nepo.unicamp.br).
} 


\section{Introdução}

O presente artigo tem por objetivo apresentar um método para aumentar a resolução de dados censitários e apresentá-los agregados em uma grade estatística. A metodologia empregada é composta pela agregação dos dados básicos a partir das coordenadas geográficas dos domicílios e pela desagregação dos dados por setor censitário utilizando proporcionalidade de área. Os dados assim gerados foram aplicados para estimar a população residente em unidades de conservação da Amazônia Legal brasileira.

A estimativa da população em unidades territoriais definidas por critérios não baseados em delimitações geopolíticas é um desafio para os estudos demográficos em regiões grandes e dinâmicas, como a Amazônia Legal brasileira, ${ }^{1}$ em decorrência da variabilidade de ecossistemas e de contextos socioeconômicos ali presentes. Os limites ecológicos não coincidem, necessariamente, com as delimitações político-administrativas para as quais se dispõe de dados demográficos. Os limites político-administrativos, por sua vez, podem variar de um censo para outro, dificultando análises comparativas ao longo do tempo (HOGAN et al., 2008, p. 73).

Para minimizar estas dificuldades, os dados obtidos a partir da localização dos domicílios registrados na Contagem da População do Instituto Brasileiro de Geografia e Estatística (IBGE), em 2007, foram agregados em uma grade regular (D’ANTONA et al., 2011; BUENO; DAGNINO, 2011). Pode-se afirmar que a agregação, em qualquer unidade de área, de dados individuais obtidos em registros administrativos ou em pesquisas domiciliares, com critérios estabelecidos de qualidade e regularidade, apresenta resultados superiores a qualquer método estatístico ou geoestatístico utilizado para estimação de dados, por mais que esses métodos estejam cada vez mais avançados. Tal afirmação baseia-se no fato de que esta abordagem - agregação em grade regular - não pode ser considerada uma "técnica” de estimação, pois trata-se de agregar os dados individuais coletados censitariamente em uma unidade de área. Portanto, esta abordagem não está sujeita aos mesmos erros potencialmente existentes nos métodos estatísticos ou geoestatísticos. Além disso, as técnicas citadas aplicam-se apenas à variável volume de população, pois não existem dados auxiliares que possam ajudar a inferir a distribuição de características da população no espaço.

A utilização da grade assim construída para estimar a população em unidades de conservação (UC) federais da Amazônia Legal brasileira é uma contribuição para os estudos de população em áreas protegidas, dada a escassez de estimativas do volume da população em unidades de conservação a partir de censos. Isso permite testar a aplicação da metodologia em áreas que não seguem os limites político-administrativos, nem os limites das unidades

\footnotetext{
${ }_{1}^{1}$ A Amazônia Legal ocupa $5.016 .136,3 \mathrm{~km} 2$, correspondendo a cerca de $60 \%$ do território brasileiro. Ela contém $20 \%$ do bioma Cerrado, a totalidade do bioma Amazônia e 1/3 das florestas tropicais úmidas do planeta, além de deter a mais elevada biodiversidade, o maior banco genético e $1 / 5$ da disponibilidade mundial de água potável (IBGE, 2003, p. 11). Na Amazônia Legal, de acordo com o Censo 2010 (IBGE, 2011), residem aproximadamente 24 milhões de pessoas, distribuídas em 775 municípios, nos Estados do Acre, Amapá, Amazonas, Mato Grosso, Pará, Rondônia, Roraima, Tocantins, Maranhão e Goiás. Cabe notar que três estados não estão totalmente contidos na Amazônia Legal: Tocantins, com 98\% da sua área dentro da Amazônia Legal, Maranhão, com 79\%, e Goiás, com 0,8\%.
} 
territoriais de coleta (setores censitários), além de verificar a existência de limitações para a utilização dos dados georreferenciados da Contagem 2007.

\section{Unidades de conservação federais na Amazônia Legal}

De acordo com a Lei n. 9.985, de 18 de julho de 2000, que institui o Sistema Nacional de Unidades de Conservação da Natureza (SNUC), uma unidade de conservação é um:

Espaço territorial e seus recursos ambientais, incluindo as águas jurisdicionais, com características naturais relevantes, legalmente instituído pelo Poder Público, com objetivos de conservação e limites definidos, sob regime especial de administração, ao qual se aplicam garantias adequadas de proteção (BRASIL, 2000, artigo 2, inciso I).

A legislação define dois grupos de unidades federais: as de proteção integral (PI) e as de uso sustentável (US), subdividas em 12 categorias (Quadro 1). As unidades de proteção integral têm por objetivo preservar a natureza, admitindo-se apenas o uso indireto dos seus recursos naturais - aqueles que não envolvam consumo, coleta, dano ou destruição dos recursos (BRASIL, 2000, artigo 2, inciso IX). As UCs de uso sustentável visam a compatibilização da conservação da natureza com o uso sustentável de parcela dos seus recursos, ou seja, a exploração do ambiente de maneira a garantir a perenidade dos recursos ambientais renováveis e dos processos ecológicos, mantendo a biodiversidade de forma socialmente justa e economicamente viável (BRASIL, 2000, artigo 2, inciso XI).

Conforme o Quadro1, as unidades de proteção integral são restritivas quanto à presença de populações residentes, enquanto naquelas de uso sustentável a existência de moradores torna-se, em alguns casos, uma condição. Segundo o SNUC (BRASIL, 2000), a presença de populações tradicionais (ou residentes) em unidades de conservação é totalmente permitida apenas nas Reservas Extrativistas (Resex), nas Reservas de Desenvolvimento Sustentável (RDS) e nas Florestas Nacionais (Flona). ${ }^{2}$ Nas unidades de conservação das categorias Área de Proteção Ambiental (APA) e Área de Relevante Interesse Ecológico (Arie), pode haver ocupação humana, embora o texto da lei não especifique em que grau e nem se a ocupação deve ser restringida às comunidades tradicionais.

\footnotetext{
${ }^{2}$ Não há uma definição precisa de “população tradicional” na Lei do SNUC (BRASIL, 2000) nem no Decreto n. 4.340 (BRASIL, 2002), que regulamenta a Lei. O Decreto n. 4.340, que regulamenta o SNUC, apesar de ainda não definir população tradicional, já admite o termo populações residentes. O Decreto n. 6.040, que institui a Política Nacional de Desenvolvimento Sustentável dos Povos e Comunidades Tradicionais (BRASIL, 2007), define "povos" ou “comunidades tradicionais" como grupos culturalmente diferenciados e que se reconhecem como tais, que possuem formas próprias de organização social, ocupam e usam territórios e recursos naturais como condição para sua reprodução cultural, social, religiosa, ancestral e econômica, utilizando conhecimentos, inovações e práticas gerados e transmitidos pela tradição. Por ser mais abrangente e condizente à ocupação verificada no contexto amazônico, além de servir como alternativa ao rótulo de tradicional, adota-se o termo população residente, em conformidade com o proposto por autores como Benatti (1999) e West e Brechin (1991, p. 6).
} 
QUADRO 1

Tipologia das unidades de conservação federais

\begin{tabular}{|c|c|c|c|}
\hline Grupo & Tipo & Finalidade & Presença de residentes \\
\hline \multirow{5}{*}{$\begin{array}{l}\text { Proteção } \\
\text { Integral }\end{array}$} & $\begin{array}{l}\text { Estação Ecológica } \\
\text { (Esec) }\end{array}$ & $\begin{array}{l}\text { Preservação da natureza e realização de } \\
\text { pesquisas científicas. }\end{array}$ & Não \\
\hline & $\begin{array}{l}\text { Monumento } \\
\text { Natural (Monat) }\end{array}$ & $\begin{array}{l}\text { Proteger sítios naturais raros ou de grande } \\
\text { beleza cênica. }\end{array}$ & Não \\
\hline & $\begin{array}{l}\text { Parque Nacional } \\
\text { (Parna) }\end{array}$ & $\begin{array}{l}\text { Preservar ecossistemas naturais de grande } \\
\text { relevância ecológica e beleza cênica. Permite } \\
\text { pesquisa, recreação e turismo ecológico. }\end{array}$ & Não \\
\hline & $\begin{array}{l}\text { Refúgio de Vida } \\
\text { Silvestre (RVS) }\end{array}$ & $\begin{array}{l}\text { Proteger ambientes naturais, assegurando a } \\
\text { existência e reprodução de espécies da flora } \\
\text { e fauna. }\end{array}$ & Não \\
\hline & $\begin{array}{l}\text { Reserva Biológica } \\
\text { (Rebio) }\end{array}$ & $\begin{array}{l}\text { Preservação integral da biota e demais } \\
\text { atributos naturais. }\end{array}$ & Não \\
\hline \multirow{7}{*}{$\begin{array}{l}\text { Uso } \\
\text { Sustentável }\end{array}$} & $\begin{array}{l}\text { Área de Proteção } \\
\text { Ambiental (APA) }\end{array}$ & $\begin{array}{l}\text { Proteger a diversidade biológica e disciplinar } \\
\text { o processo de ocupação. }\end{array}$ & $\begin{array}{l}\text { Sim, mas com limites } \\
\text { ao grau de ocupação } \\
\text { humana. }\end{array}$ \\
\hline & $\begin{array}{l}\text { Área de Relevante } \\
\text { Interesse Ecológico } \\
\text { (Arie) }\end{array}$ & $\begin{array}{l}\text { Manter os ecossistemas naturais de } \\
\text { importância regional ou local e regular o uso } \\
\text { dessas áreas. }\end{array}$ & $\begin{array}{l}\text { Sim, mas com pouca } \\
\text { ocupação humana. }\end{array}$ \\
\hline & $\begin{array}{l}\text { Floresta Nacional } \\
\text { (Flona) }\end{array}$ & $\begin{array}{l}\text { Uso dos recursos florestais e pesquisa } \\
\text { científica, com ênfase em métodos para } \\
\text { exploração sustentável de florestas nativas. }\end{array}$ & $\begin{array}{l}\text { Sim, é permitida } \\
\text { a permanência de } \\
\text { populações tradicionais } \\
\text { que já a habitavam } \\
\text { quando de sua criação. }\end{array}$ \\
\hline & $\begin{array}{l}\text { Reserva Extrativista } \\
\text { (Resex) }\end{array}$ & $\begin{array}{l}\text { Proteger os meios de vida e a cultura } \\
\text { das populações tradicionais residentes e } \\
\text { assegurar o uso sustentável dos recursos } \\
\text { naturais. }\end{array}$ & $\begin{array}{l}\text { Sim, especialmente } \\
\text { populações tradicionais } \\
\text { cuja subsistência baseia- } \\
\text { se no extrativismo. }\end{array}$ \\
\hline & $\begin{array}{l}\text { Reserva de Fauna } \\
\text { (Refau) }\end{array}$ & $\begin{array}{l}\text { Estudos técnico-científicos sobre o manejo } \\
\text { econômico sustentável de recursos } \\
\text { faunísticos. }\end{array}$ & $\begin{array}{l}\text { Sim, mas apenas para } \\
\text { visitação pública. }\end{array}$ \\
\hline & $\begin{array}{l}\text { Reserva de } \\
\text { Desenvolvimento } \\
\text { Sustentável (RDS) }\end{array}$ & $\begin{array}{l}\text { Preservar a natureza assegurando as } \\
\text { condições necessárias para a reprodução dos } \\
\text { modos de vida das populações tradicionais. }\end{array}$ & $\begin{array}{l}\text { Sim, especialmente } \\
\text { populações tradicionais. }\end{array}$ \\
\hline & $\begin{array}{l}\text { Reserva Particular } \\
\text { do Patrimônio } \\
\text { Natural (RPPN) }\end{array}$ & $\begin{array}{l}\text { Conservar a diversidade biológica. Só } \\
\text { serão permitidas a pesquisa científica e a } \\
\text { visitação com objetivos turístico, recreativo e } \\
\text { educacional. }\end{array}$ & $\begin{array}{l}\text { Sim, mas apenas } \\
\text { do proprietário e } \\
\text { funcionários diretamente } \\
\text { ligados à gestão da UC. }\end{array}$ \\
\hline
\end{tabular}

Fonte: Adaptado de: D’Antona (2009); SNUC - Sistema Nacional de Unidades de Conservação da Natureza, 2000; Instituto Sócioambiental, 2008. Disponível em: 〈http://www.socioambiental.org/uc/glossario〉. Acesso em: 20 fev. 2012.

\section{A presença humana em UC na Amazônia, ainda que possa ser vista como uma fonte de} conflitos, ${ }^{3}$ é um componente essencial para a existência de unidades como as Resex - um modelo inovador, resultante da mobilização dos seringueiros durante a década de 1980.

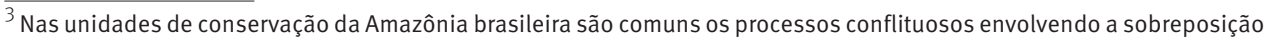
de territorialidades e as disputas entre a população residente na UC, a população que reside no seu entorno, o poder estatal e outros atores (fazendeiros, grileiros, migrantes). Nas UCs, diversos tipos de territórios sobrepõem-se em função dos atores interessados nesse espaço: territórios de conservação, para os órgãos ambientais; territórios de vida, para os seres humanos, animais e vegetais; territórios de produção, para aqueles interessados em extrair e manejar os recursos; territórios de pesquisa acadêmica, para os pesquisadores; e assim sucessivamente (COELHO et al., 2009, p. 68).
} 
Estas unidades não apenas aceitam populações residentes, como também dependem da vontade dos moradores para a sua criação (CARNEIRO DA CUNHA; ALMEIDA, 2009, p. 293; D’ANTONA, 2003). ${ }^{4}$

As estimativas do volume da população em unidades de conservação a partir de censos são escassas. Hogan et al. (2008, p. 111) argumentam que a ocupação em áreas protegidas (Terras Indígenas e unidades de conservação) na Amazônia contrapõe-se à ocupação concentrada em cidades e em outras porções classificadas como rurais fora das UCs. De acordo com Carneiro da Cunha e Almeida (2009, p. 294), com base em dados do Censo Demográfico 2000, os territórios das UCs estão entre as porções com menor densidade demográfica. Contudo, abordagens feitas a partir de análises de setores censitários não permitem quantificar a população residente nestas áreas.

Ainda mais raros são os levantamentos populacionais baseados em uma mesma metodologia para todas as unidades. Predominam os levantamentos específicos por UC, sobretudo aqueles realizados durante os processos de definição ou regulamentação das mesmas. Estes levantamentos têm características de survey e são realizados pontualmente, tanto no tempo quanto no espaço, principalmente devido ao seu alto custo, ocasionando dificuldades na comparabilidade dos dados ao longo dos anos.

Por outro lado, os censos são de aplicação limitada para estudos que necessitam das características das populações residentes em UCs, pois seus dados não são apresentados em áreas territoriais que correspondam aos limites dessas unidades. Mesmo o uso da malha de setores censitários para uma melhor aproximação da distribuição da população é problemático, sobretudo devido às grandes dimensões e à baixa ocupação dos setores rurais na Amazônia. Além disso, as regras de sigilo estatístico ${ }^{5}$ definidas pelo IBGE - não são disponibilizados dados para setores censitários com menos de cinco domicílios (IBGE, 2008b) - levam à omissão de informação em expressivas porções rurais da Amazônia. 0 caso do município de Altamira serve para ilustrar os problemas mencionados (Figura 1).

Altamira, no Estado do Pará, é o maior município do Brasil em termos territoriais, com 157.181,05 km², calculados a partir da soma das áreas de cada um de seus setores censitários em 2007. Sua população concentra-se na sede municipal, no extremo norte do município. De acordo com dados da Contagem 2007 por setores censitários, o município possuía 91.706 habitantes, sendo que 76\% viviam na zona urbana, em uma área de

\footnotetext{
${ }^{4}$ De acordo com Carneiro da Cunha e Almeida (2009, p. 285-6), em contraste com o modelo de Yellowstone, que criava ambientes intocados sem população humana, as UCs no Brasil - e principalmente as de uso sustentável - parecem adotar a ideia de que as populações devem proteger o ambiente e os seus recursos. Dessa forma, as populações não são vítimas e sim parceiras das preocupações ambientais. Os autores argumentam que nem todas as áreas podem ser administradas pelos habitantes preexistentes nelas, mas excluir esses moradores do processo de criação ou expulsar essas pessoas das áreas sem thes oferecer meios alternativos de subsistência é rota segura para desastres (CARNEIRO DA CUNHA; ALMEIDA, 2009, p. 287).

${ }^{5}$ A Lei $n^{\circ} 5.534$, de 14/11/68 (BRASIL, 1968), e o Decreto Lei nº161, de 13/02/67 (BRASIL, 1967), que dispõem sobre a obrigatoriedade de prestações de informações ao IBGE, também impõem como contrapartida que essas informações sejam usadas exclusivamente para fins estatísticos e que tenham caráter sigiloso, ou seja, que as informações disponibilizadas não identifiquem os declarantes de qualquer forma. O IBGE utiliza diversas técnicas recomendadas internacionalmente para que os dados possam ser disponibilizados ao público com a devida segurança da manutenção do sigilo estatístico.
} 
38 km² (ou 0,02\% do território de Altamira). Boa parte do município é ocupada por áreas protegidas. Os setores censitários rurais são extensos e pouco populosos. Os desafios para as estimativas de população em áreas protegidas estão ali colocados: setores censitários rurais que não se conformam aos limites das UCS, setores muito extensos, dificultando até mesmo a aplicação de métodos estatísticos para a distribuição da população interna aos polígonos e setores censitários sem informação, ou porque não há população em seu interior, ou por conta das regras de sigilo do IBGE. No exemplo considerado, os 24 setores sem informação (de um total de 153 setores censitários) equivalem a $60.845,4$ km² ou 39\% da área total de Altamira.

Na Figura 1, notam-se a grande quantidade de setores sem dados populacionais e a sobreposição entre setores e unidades de conservação. No destaque, percebe-se que as duas unidades de conservação possuem problemas diferentes. De um lado, a Reserva Extrativista (Resex) do Iriri, criada em 2006, ocupa vários setores cujos limites não coincidem com os limites da UC. De outro lado, a Floresta Nacional (Flona) Altamira, criada em 1998, tem os limites coincidentes, porém, alguns setores estão sem dados.

FIGURA 1

Limitações do uso de dados agregados por setores censitários

Município de Altamira-PA - 2007

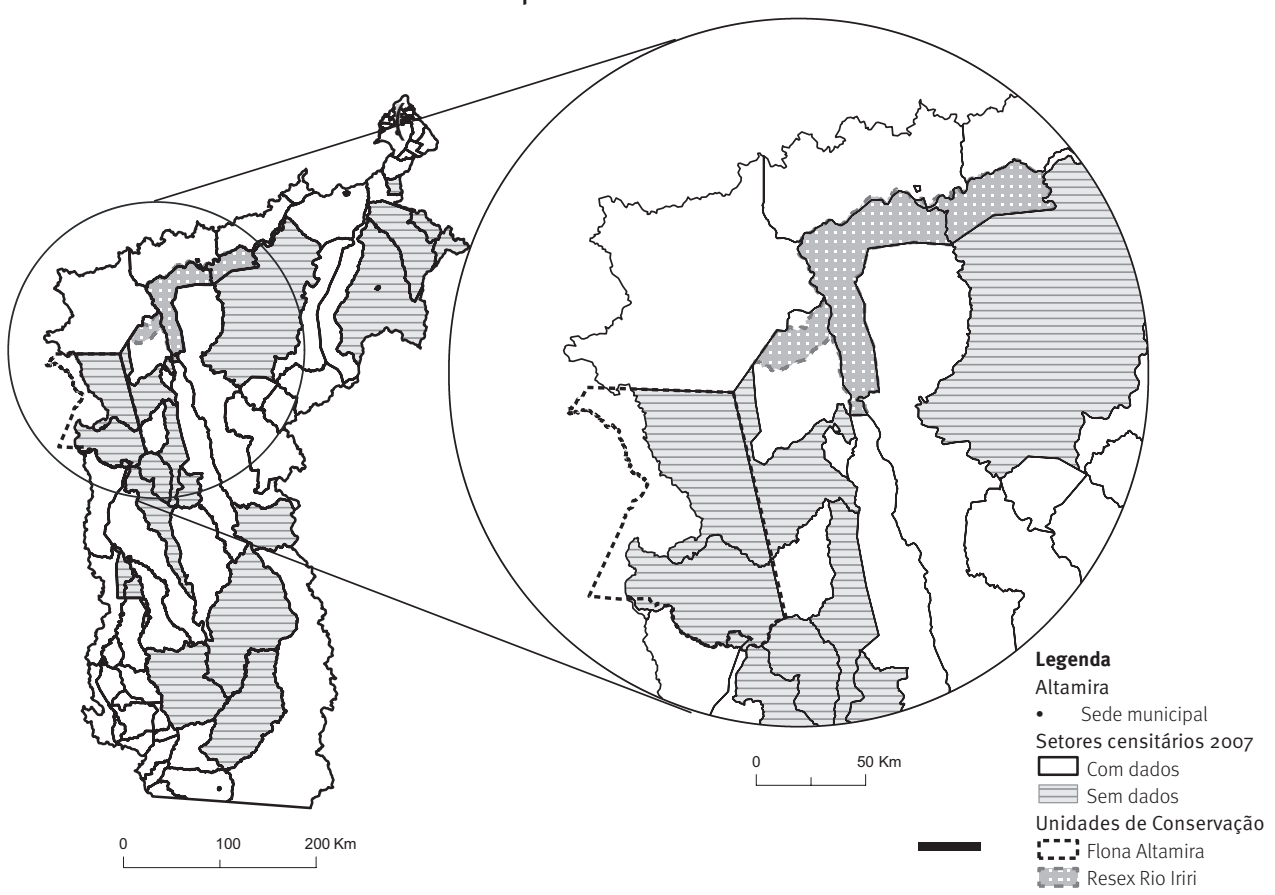

Fonte: Com base na malha digital dos setores censitários rurais da Contagem Populacional de 2007 (IBGE) e na malha de Unidades de Conservação.

No enfrentamento das limitações ilustradas pelo caso de Altamira, o uso de grades regulares é uma alternativa que envolve a aplicação de geotecnologias e de recentes bases 
de dados georreferenciados do IBGE para a espacialização das informações em unidades territoriais mais apropriadas para as análises.

\section{Geotecnologias e o uso de grades regulares}

Nas últimas décadas, verifica-se o crescimento do uso de unidades de análise para descrever, monitorar e analisar o meio ambiente, tais como bacias hidrográficas, unidades de relevo e de paisagem. Porém, os sistemas baseados em unidades político-administrativas continuam prevalecendo para a descrição da sociedade humana e seu habitat (BACKER, 2008). No entanto, esses limites administrativos funcionam como barreiras artificiais na representação de fenômenos socioeconômicos e ambientais contínuos (ESPON, 2006), dificultam a combinação de diferentes conjuntos de dados em uma mesma base e estão sujeitos a variações de tamanho e de forma entre regiões e ao longo do tempo.

Para a representação espacial de dados demográficos, a utilização de informações individuais, representadas por objetos discretos ou pontos, com associação dos dados da população às coordenadas geográficas dos seus domicílios, seria o ideal, pois oferece a possibilidade de se trabalhar em todas as escalas e em qualquer tipo de compartimentação espacial (ESPON, 2006). Infelizmente, existem restrições à sua divulgação devido à necessidade de manutenção do sigilo estatístico.

A maioria dos institutos de estatística dissemina seus dados agrupados por unidades de área, o que leva ao pressuposto de homogeneidade interna de tais unidades, não importando sua forma ou dimensão. Os problemas decorrentes desta consideração são bem conhecidos, sendo o mais representativo o "problema de unidade de área modificável" ou MAUP (OPENSHAW, 1984). De acordo com Openshaw e Openshaw (1997), para uma mesma população estudada, a alteração dos limites da área de agregação altera também os resultados finais, podendo-se concluir que os resultados variam em função das diferentes maneiras possíveis de realizar o agrupamento das unidades.

O crescente uso de geotecnologias, entre outras ferramentas computacionais, vem viabilizando o emprego dos dados demográficos como objetos discretos (pontos), como unidades de áreas que agregam os dados individuais e como superfícies contínuas, calculadas a partir de uma das duas representações anteriores (KAMPEL, 2004). A Organização das Nações Unidas (UNITED NATIONS, 2000; 2009) destaca que o uso de geotecnologias nas pesquisas censitárias melhora a qualidade dos dados coletados e da própria operação, além de ampliar as possibilidades de disseminação.

O uso de grades regulares, um caso particular de agregação de dados em unidades de área, é uma estratégia para a representação espacial que pode ser aplicada na Demografia. A agência estatística finlandesa Statistics Finland (2010), que utiliza grades na disseminação de dados desde 1970, aponta que a grande vantagem do uso de tal sistema é prescindir dos limites político-administrativos para a apresentação das informações. A distribuição das células dentro da região de estudo é feita de maneira regular, homogênea e hierárquica, 
dando ao sistema grande flexibilidade. Desta maneira, os dados podem ser compilados para diferentes recortes espaciais, como áreas definidas por acidentes geográficos ou resultantes de análises espaciais (buffer, por exemplo), não estando sujeitos a problemas decorrentes das mudanças em limites político-administrativos, ou mesmo das unidades territoriais de coleta.

Como desvantagem na utilização das grades regulares é citada a dificuldade de determinar e corrigir erros espaciais na coleta, como os decorrentes do registro incorreto de coordenadas geográficas ou até mesmo da falha na captura das coordenadas dos domicílios (STATISTICS FINLAND, 2010). A determinação deste tipo de erro enquanto a operação está em andamento é problemática, tendo em vista a complexidade e o tamanho da operação, principalmente em um país com a extensão territorial do Brasil. A correção do erro após o término da operação censitária geralmente implica uma nova operação de campo, fato que é inviável devido aos altos custos envolvidos.

A composição de uma grade regular pode ser feita a partir de técnicas de desagregação (top-down) ou de agregação (bottom-up). As primeiras utilizam dados previamente agregados em áreas, como os setores censitários, por exemplo, e os transformam empregando métodos geoestatísticos, como interpolação e krigagem, ${ }^{6}$ de modo a redistribuir a população na grade desejada (GALLEGO, 2009; 2010). Nesta metodologia, pode-se utilizar a variável população diretamente, a partir dos resultados de censos, ou indiretamente, estimando-a a partir de outras variáveis que indiquem a presença humana, como classificações de uso e cobertura da terra, dados de desmatamento ou de urbanização, obtidos a partir de técnicas de sensoriamento remoto (DE SHERBININ et al., 2002). Porém, existem algumas limitações relativas a essas técnicas, como a não preservação do volume populacional no resultado final e a impossibilidade de representar espaços sem ocupação (KAMPEL, 2004).

Há uma vasta literatura a respeito do assunto. Por exemplo, Tobler (1975; 1979), Goodchild et al. (1993), Langford e Unwin (1994), Martin (1989; 1996), Martin et al. (2000), Thurstain-Goodwin e Unwin (2000), Kampel (2004), Amaral et al. (2005), Yoo et al. (2010), Mennis e Hultgren (2006a; 2006b), Mennis (2002; 2003), Gallego (2010), Gisbert e Marti (2011), Milego e Ramos (2010), Pozzi et al. (2003), Deichmann et al. (2001) e Stromgren e Holm (2011) discorrem sobre as diferentes técnicas utilizadas para desagregação de dados populacionais, documentando técnicas cada vez mais aprimoradas, cujos resultados se apresentam notadamente melhores.

Considerando a existência de dados socioeconômicos e demográficos coletados individualmente pelos censos, cuja qualidade e regularidade os tornam candidatos inquestionáveis a dar suporte a novas formas de agregação de dados para disseminação, surge a abordagem top-down, que consiste na quantificação dos dados discretos referentes à localização das residências, em células de uma grade regular que abrange a região de estudo

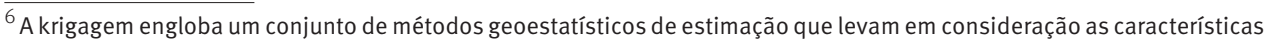
espaciais de autocorrelação de variáveis regionalizadas, ou seja, variáveis que têm continuidade espacial, permitindo que os dados obtidos por amostragem possam ser utilizados para parametrizar a estimação onde o valor da variável é desconhecido (LANDIM, 2000).
} 
(TAMMISTO, 2007; GALLEGO, 2010). Notadamente, a agregação de dados individuais obtidos em registros administrativos ou em pesquisas domiciliares, com critérios estabelecidos de qualidade, tem resultados superiores a qualquer método estatístico utilizado para desagregação dos volumes populacionais, por mais que esses métodos estejam cada vez mais avançados. Ressalta-se que as técnicas geoestatísticas são importantes e devem ser empregadas na ausência ou impossibilidade de obtenção de dados observados em campo, ou em casos em que a precisão e a acurácia não são determinantes para o alcance dos objetivos na escala de análise.

No Brasil, a técnica de agregação torna-se viável a partir dos levantamentos de 2007, graças ao uso sistemático e integrado de geotecnologias pelo IBGE que culminou com a espacialização do Cadastro de Endereços para Fins Estatísticos e seu relacionamento com os Mapas Censitários nas operações de 2010 (BUENO; DAGNINO, 2011). Tanto na operação conjunta de Contagem Populacional e Censo Agropecuário, em 2007, quanto no Censo Demográfico de 2010, foram capturadas as coordenadas geográficas das unidades situadas nas áreas rurais, sendo as mesmas complementares aos endereços, já que nessas áreas não existe um endereçamento formal como nas áreas urbanas (IBGE, 2009). As coordenadas dos domicílios visitados é a base para a técnica de agregação em grades regulares, possibilitando a conversão de objetos discretos - os pontos representando os domicílios - em pequenas unidades de áreas, as células, que agregam as informações individuais.

\section{Procedimentos para a estimativa da população em UC da Amazônia Legal}

A metodologia apresentada aqui é um aperfeiçoamento daquela utilizada em D’Antona et al. (2011) e Bueno e Dagnino (2011). Para a estimativa da população nas UCs da Amazônia Legal brasileira foi feita uma abordagem híbrida, combinando as duas metodologias agregação e desagregação - expostas anteriormente.

$\mathrm{Na}$ abordagem de agregação, partiu-se da localização dos domicílios visitados pelo IBGE durante a Contagem Populacional 2007. Utilizou-se o Cadastro de Endereços para Fins Estatísticos referentes a áreas exclusivamente rurais - aquelas equivalentes à área externa ao perímetro urbano, exclusive as áreas de aglomerado rural (IBGE, 2008) - e relativos a domicílios particulares. Na abordagem de desagregação foi considerada a malha vetorial de setores censitários, correspondente aos aglomerados rurais (povoados e vilas) e urbanos, fazendo-se a associação dos dados demográficos desses setores com as células da grade por meio de equivalência de área.

A grade regular foi gerada no programa ArcGIS/ArcMap, versão 9.3, com utilização da ferramenta Vector Grid, componente da extensão ET Geo Wizards LT.7 Tendo em vista as dimensões continentais do Brasil e as vantagens de se ter uma grade estatística acompanhando a grade cartográfica utilizada no país, optou-se por empregar como referência cartográfica a Projeção Geográfica (D’ANTONA et al., 2011). As dimensões das células da

\footnotetext{
$\overline{7}$ Disponível em: 〈http://www.ian-ko.com〉. Acesso em: 15 jan. 2012.
} 
grade equivalem a 1 minuto e 15 segundos, o que correspondente a aproximadamente 5,3 km². A área da Amazônia Legal engloba um total de 953.383 células.

As dimensões da célula foram definidas após vários testes com dados para os Estados do Pará e São Paulo, duas unidades bem distintas em termos da distribuição populacional. Esses testes tiveram por objetivo determinar um tamanho de célula que fosse capaz de desagregar as informações do censo de forma representativa para toda a área rural do país, considerando as diferenças de ocupação regionais, mas sem deixar de levar em conta as questões de sigilo estatístico. Embora o presente trabalho tenha sido desenvolvido a partir desta dimensão de célula, outros valores podem ser adotados em outras análises.

Utilizando os arquivos vetoriais da grade e os pontos dos domicílios, foi realizada uma operação de junção espacial, também com o software ArcGIS/ArcMap. O resultado foi um novo arquivo vetorial de pontos contendo a identificação da célula da grade em que o mesmo estava localizado. Para os pontos que se encontravam exatamente no limite entre duas células menos de $0,1 \%$ do total -, considerou-se a identificação igual ao do ponto mais próximo.

Não tendo o IBGE informado o número de habitantes por domicílio registrado, ${ }^{8}$ a estimativa do volume da população por domicílio foi feita pela média de moradores no setor censitário onde o mesmo se localiza. Posteriormente, esse valor foi agregado para cada célula. A média de moradores por domicílio em cada setor censitário foi obtida por meio da divisão da população no setor censitário, residente em domicílios permanentes ou improvisados, pelo número de domicílios, permanentes ou improvisados, existentes no setor.

Constatou-se uma subenumeração relativa ao registro das coordenadas geográficas dos domicílios durante a Contagem Populacional de 2007. Isso não significa um erro de cobertura censitária, mas uma perda de dados quando da realização da espacialização dos mesmos. Assim, o total de domicílios sumarizado na grade regular (877.771) é inferior ao total de domicílios computados no universo da pesquisa (1.113.258). Ainda que se possa contabilizar esta diferença, a "subenumeração espacial" varia de um setor censitário para outro, de tal modo que o erro não se distribui de modo uniforme no espaço. Apesar de se ter o valor do erro, a correção é uma questão de difícil solução, pois não há nenhuma indicação que possa levar a inferir a localização das residências que não têm as coordenadas sem realizar exaustivos e onerosos trabalhos de campo.

Numa tentativa de avaliar a população potencialmente alocada na área de estudo, procurando minimizar os erros citados anteriormente, foram adotados os seguintes procedimentos: nas células que apresentam população, os dados foram ajustados aplicandose o percentual de erro calculado para o setor onde a mesma se encontra; nos casos em que a célula localizava-se em mais de um setor censitário, foi considerado o erro do setor com maior área dentro da célula; nas células onde a metodologia apontou ausência de população, o erro relativo à falta de domicílios com coordenadas não foi corrigido, assumindo-se, desta

\footnotetext{
$\overline{8}$ Para preservar o sigilo estatístico, o IBGE não divulgou nenhum dado relacionado aos domicílios, disponibilizando para cada ponto registrado apenas o endereço, as coordenadas geográficas e o tipo de unidade (residencial, estabelecimento de ensino, estabelecimento de saúde, etc.).
} 
maneira, que a população não localizada por meio de coordenadas pela Contagem 2007 esteja totalmente distribuída por áreas onde a presença de população foi detectada.

Para o cálculo da população nas células sobrepostas a aglomerados rurais e urbanos, agregados por setores censitários e representados espacialmente por polígonos, utilizou-se a metodologia de proporcionalidade de área, a qual supõe que a população esteja distribuída homogeneamente dentro da área considerada, neste caso, o setor censitário. Assim, a parcela de população equivalente à área do setor censitário que se encontra dentro de uma célula da grade é agregada a esta célula. O pressuposto de homogeneidade, embora não seja absolutamente verdadeiro, pode ser considerado bem próximo da realidade para áreas densas e de pequena extensão, como são esses aglomerados populacionais. Além disso, por não serem utilizados os pontos dos domicílios, não existe o erro de subenumeração espacial anteriormente apontado.

A partir desses procedimentos, foi gerada uma grade consolidada, sobre a qual foram sobrepostos os limites das unidades de conservação criadas na Amazônia Legal até 2006, de acordo com o Cadastro Nacional de Unidades de Conservação - CNUC do Ministério do Meio Ambiente (BRASIL, s.d), incorporados à Base Cartográfica Contínua do Brasil ao Milionésimo (IBGE, 2010). ${ }^{9}$ Foram identificadas 121 UCs federais sobrepostas à Amazônia Legal, perfazendo um total de 567.399 km² (11,3\% de toda a Amazônia Legal). Deste total, 43 unidades são da categoria proteção integral (292.491 km²) e 78 da categoria uso sustentável $\left(274.908 \mathrm{~km}^{2}\right)$. Para o cálculo da população nas UCs foram descartadas três unidades que se encontram parcialmente na Amazônia Legal e quatro que estão total ou parcialmente dentro de municípios onde não houve Contagem Populacional em 2007. Assim, chegou-se a um número de 114 UCs (538.412 km²) consideradas na análise: 40 de proteção integral $\left(277.173 \mathrm{~km}^{2}\right)$ e 74 de uso sustentável $\left(261.239 \mathrm{~km}^{2}\right){ }^{10}$

Para cada unidade de conservação selecionada, foi gerada uma área envoltória (buffer) distando $10 \mathrm{~km}$ do seu limite. ${ }^{11}$ Os polígonos das envoltórias foram gerados independentemente para cada unidade, de modo que não houvesse superposição de áreas no caso da existência de outra UC nas proximidades. Em casos de UCs vizinhas ou muito próximas, as superposições de envoltórias foram eliminadas, evitando, assim, dupla contagem da população. Com as envoltórias de cada UC foi criada uma área única a partir da eliminação de todas as superposições espaciais existentes, de modo que se pudesse ter uma estimativa geral da população residente no entorno de todas as UCs consideradas no

\footnotetext{
${ }^{9}$ No presente estudo foram consideradas apenas as unidades de conservação federais criadas até 2006, de modo a tornar a base do CNUC mais compatível com os dados da Contagem da População, cuja data de referência é 1ํ de abril de 2007. ${ }^{10}$ Três unidades de proteção integral foram descartadas: Reserva Biológica do Tapirapé, no Pará; Estação Ecológica Serra Geral do Tocantins, Tocantins; e Parque Nacional das Nascentes do Rio Parnaíba, Maranhão. Quatro unidades de uso sustentável foram descartadas: Área de Proteção Ambiental Meandros do Araguaia, Mato Grosso; Floresta Nacional de Tapirapé-Aquiri; Floresta Nacional de Itacaiunas; e Reserva Extrativista Tapajós Arapiuns, todas no Pará.

${ }^{11}$ Essa distância era a preconizada como área de amortecimento pela Resolução Conama n. 13 (BRASIL, 1990), anterior à resolução que está em vigência atualmente - Resolução Conama n. 428 (BRASIL, 2010). Esta distância ainda vale como zona de amortecimento para as UCS localizadas em alguns estados, por exemplo, como o mencionado pela Secretaria Estadual do Meio Ambiente do Rio Grande do Sul (2011).
} 
estudo. Todos esses procedimentos foram realizados com a utilização de ferramentas para manipulação de dados espaciais, como interseção, união e junção, existentes em programas de geoprocessamento.

Para a determinação do volume populacional nas UCs e seus respectivos entornos, utilizou-se a função de interseção espacial entre essas áreas e a grade, gerando novos arquivos vetoriais, cujos atributos foram totalizados para se chegar ao resultado final. $\mathrm{A}$ tabela de atributos do arquivo vetorial final permite o cálculo do volume da população em cada UC e no seu entorno.

A Figura 2 ilustra o processamento das duas abordagens adotadas - a agregação dos dados pontuais e a repartição dos setores censitários por células -, cujo objetivo é fornecer o resultado final: a estimativa da população por UC e entorno.

FIGURA 2

Etapas para a geração de dados em grade regular, por meio das abordagens de agregação e desagregação, e para a estimativa da população em unidades de conservação

A - Geração de dados por agregação (bottom-up)

Cálculo da população por domicílio
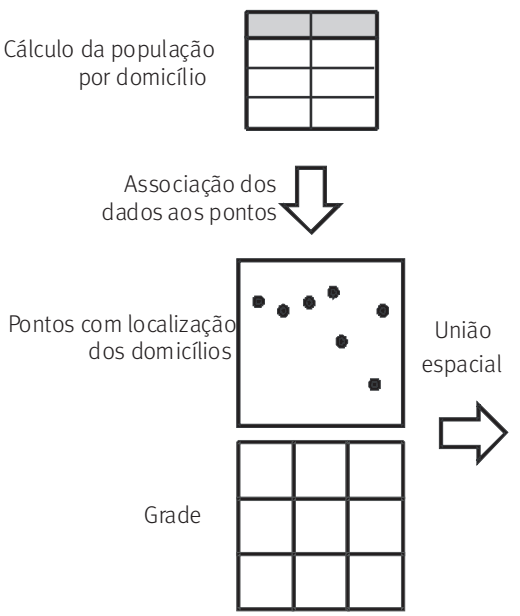

Totalização dos dados associados aos pontos de cada célula

B - Geração de dados por desagregação (top-down)

Setores de aglomerados rurais e urbanos

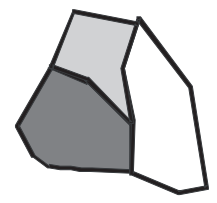

Grade

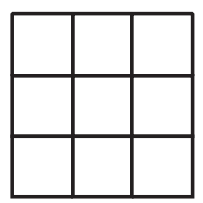

Cálculo da

a) área do setor por célula e

b) população correspondente

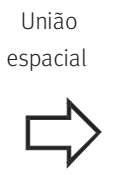

Associação dos dados à grade $(\mathrm{P} 1=$ população calculada na célula 1) 
C - Estimativa da população por Unidade de Conservação (UC)

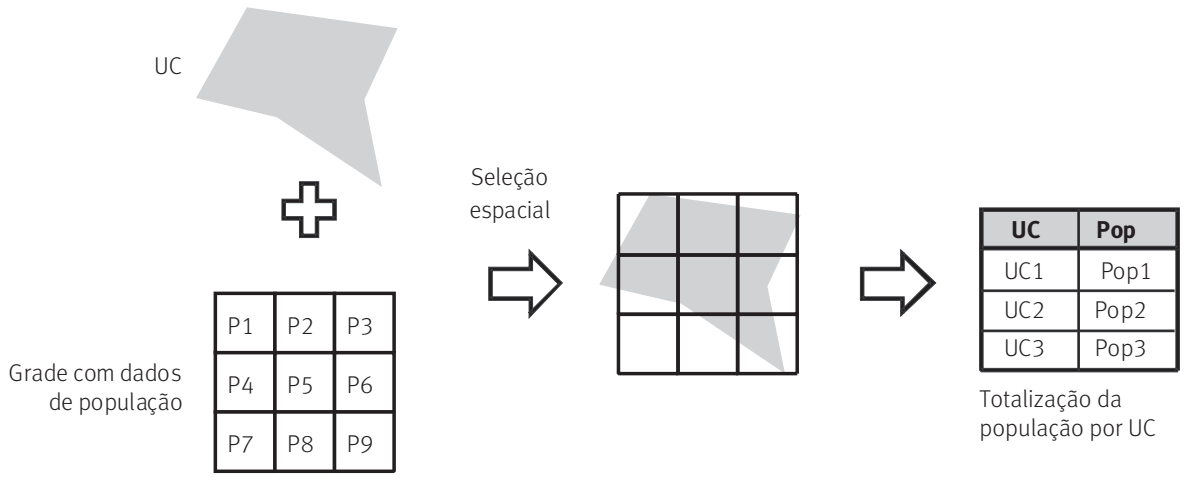

\section{Volume e distribuição da população estimada}

Levando-se em conta os domicílios com coordenadas registradas pela Contagem 2007, estima-se que a população total no interior das 114 UCs corresponda a 308.517 habitantes. Destes, 283.640 estão em unidades de uso sustentável e 24.877em unidades de proteção integral. No entorno, a população totaliza 988.158 habitantes, sendo 894.938 ao redor de UCs de uso sustentável e 93.220 ao redor das unidades de proteção integral. Buscando-se compensar a subenumeração do registro de coordenadas de domicílios, a população de cada célula foi corrigida pelo fator de subenumeração do setor censitário ao qual se sobrepõe. Levando-se em conta tal correção, a população total das UCs passa a ser estimada em 325.398 hab. (297.693 em unidades de US e 27.705 em unidades de $\mathrm{Pl}$ ) e a do entorno em 1.020.237 hab. (923.499 em unidades de US e 96.738 em unidades de PI) (Tabela 1).

Em 2007, dos 22,30 milhões de habitantes da Amazônia Legal por ocasião da Contagem, cerca de 1,5 milhão encontra-se no interior das UCs. Considerando-se que tais unidades correspondem a 11,3\% de todo o território, nota-se ali uma menor ocupação que a média regional, como seria esperado. 0 entorno das UCs é relativamente mais populoso, abrigando aproximadamente 4,5\% da população total da Amazônia.

Desagregando a informação por tipo e categoria de UC, a Tabela 1 permite ver que as unidades de proteção integral são menos populosas e menos povoadas do que as de uso sustentável. O primeiro grupo ocupa uma área sensivelmente maior $(277.000$ km², contra 261.000 km² para as UCs de uso sustentável) e agrega uma população aproximadamente 11 vezes menor que o segundo. Ainda que tal diferença seja previsível, tendo em vista os propósitos de cada tipo e as restrições quanto à presença humana, o contingente estimado nas unidades das categorias Estação Ecológica - Esec (905 hab.), Parque Nacional - Parna (19.228 hab.) e Reserva Biológica - Rebio (7.572 hab.) parece ser contraditório à legislação. Chama a atenção a quantidade de população em áreas urbanas, o que geralmente se explica pela ocupação do entorno das unidades. 


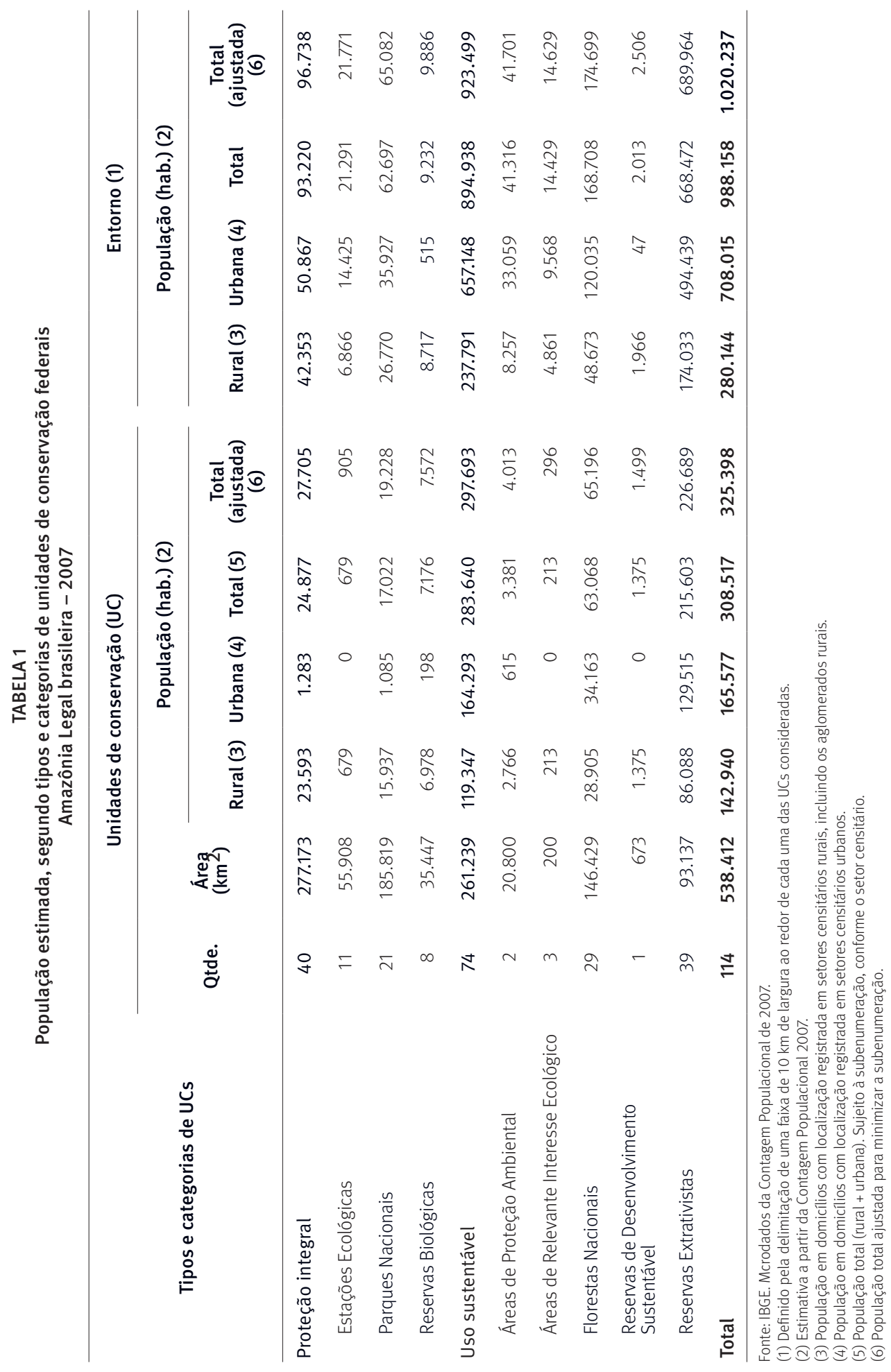


Quanto às unidades de uso sustentável, vê-se que a maior parte da população encontrase nas Reservas de Extração - Resex (226.689 hab.) e nas Florestas Nacionais - Flona (65.196 hab.), o que é compatível com o maior peso destas unidades no conjunto das UCs, uma vez que são em maior número e ocupam uma área maior do que as demais, e também com os seus propósitos. A distribuição da população em células sobrepostas a setores censitários classificados como urbanos no interior das UCs também chama a atenção, sobretudo nas Resex e nas Flona. Ainda que se pudesse esperar um contingente expressivo de habitantes em áreas rurais, a população urbana é relativamente grande. Novamente, isso pode resultar de processos de ocupação que se dão desde o entorno das unidades, sobretudo quando se considera que a população no entorno é bem maior nas unidades de uso sustentável do que nas de proteção integral.

Lançando mão de uma estratégia simples - a contabilização da quantidade de células que apresentam população em relação às que não apresentam -, conclui-se que a população não está distribuída de forma homogênea no interior das unidades. Das 113.447 células existentes dentro das UCS, apenas 4.491 possuem população, o que significa que os habitantes residem em aproximadamente $4 \%$ de toda a área. Mas isso não quer dizer que a população não circule pelas unidades, ou que não maneje recursos de uma ou várias unidades. No entorno, 11\% das células têm habitantes (6.709 de um total de 59.387 células). 0 detalhamento da população estimada por UC é apresentado no Anexo.

\section{Considerações finais}

A aplicação do método para a estimativa da população em unidades de conservação a partir de dados censitários agregados em grade regular traz uma possibilidade analítica ainda não devidamente explorada em estudos sobre áreas protegidas. Os resultados são expressivos, apesar da existência de um erro ao redor de 3\% em relação à população total contada pela Contagem 2007.

Entre as constatações mais gerais e pertinentes para a discussão sobre o tema ocupação em áreas protegidas, destacam-se: a presença de residentes em áreas de proteção integral, o que contraria o que se poderia esperar a partir das definições de tais unidades; e o fato de a população no entorno chegar a ser mais de três vezes superior àquela estimada no interior das UCS. A ocupação no entorno, sobretudo quando se considera a existência de algumas áreas definidas como urbanas, pode significar que há pressão antrópica sobre várias das unidades estudadas.

Resultados como os apontados indicam a necessidade de análises mais pormenorizadas por UC, sejam para a compreensão das dinâmicas internas às unidades - as quais, inclusive, não podem ser cobertas em um estudo geral como o aqui apresentado -, sejam para o melhor entendimento de tais dinâmicas em um quadro mais amplo da ocupação da Amazônia. Para um entendimento mais aprofundado, sugere-se que sejam levados em conta os fatores que podem afetar a ocupação humana nas UCs e seus respectivos entornos, tais como 
acessibilidade e a proximidade de áreas urbanas, além das infraestruturas existentes, como, por exemplo, as estradas. Tais elementos podem ser inseridos em um Sistema de Informações Geográficas, de tal modo que seus efeitos sobre a distribuição da população sejam testados.

Ainda com base nos mesmos dados, podem ser utilizadas métricas espaciais para avaliar a concentração ou dispersão da população em relação a outras variáveis das UCS, tais como o ano de criação, dimensões ou unidade da federação em que se situam. Da perspectiva dos gestores e pesquisadores de unidades de conservação, a abordagem aqui apresentada traz avanços na avaliação e compreensão da ocupação das unidades, permitindo vislumbrar aplicações politicamente orientadas no sentido de economizar recursos em futuros levantamentos sociodemográficos realizados nessas áreas.

Especificamente sobre a metodologia testada, foram enfrentadas algumas limitações decorrentes das características da fonte de dados utilizada. Primeiramente, tem-se a inexistência de dados para todos os municípios na Contagem 2007, o que acarretou a exclusão de algumas UCs. Depois, deparou-se com uma subenumeração espacial de domicílios, a qual dificilmente poderá ser corrigida satisfatoriamente ainda que possam ser oferecidas medidas dos erros por unidade territorial, como foi feito neste artigo. E, finalmente, há a questão da não disponibilização dos dados demográficos associados às coordenadas geográficas dos domicílios rurais registrados na Contagem 2007.

Apesar de tais limitações, a estratégia de agregação dos dados em grades regulares é promissora. O trabalho enseja um avanço analítico ao oferecer uma base que permite uma melhor distribuição da população nas unidades territoriais que são relevantes para as análises - as UCs ou outros tipos de delimitações, tais como bacias hidrográficas. Na medida do necessário, a técnica possibilita que se trabalhe com células menores, de tal modo que o ajuste ou sobreposição às camadas de informação da paisagem seja ainda melhor. A metodologia de grades regulares por agregação de dados tem ampla aplicação na Demografia e em outras áreas do saber, sobretudo por facilitar a comparabilidade ao longo do tempo.

Espera-se que o crescente uso e o desenvolvimento de aplicações utilizando os dados georreferenciados disponibilizados pelo IBGE estimulem a própria instituição a aperfeiçoar os procedimentos de registro das coordenadas e, até mesmo, a disseminar seus dados agregados em grades, permitindo estudos para pequenas áreas.

\section{Referências}

AMARAL, S.; MONTEIRO, A. M. V.; CAMARA, G.; QUINTANILHA, J. A. Estimativa da distribuição espacial da população na Amazônia brasileira com o uso de sensoriamento remoto orbital: contribuições das imagens CCD/CBERS no caso do município de Marabá-PA. In: XII SIMPÓSIO BRASILEIRO DE SENSORIAMENTO REMOTO, 2005, Goiânia. Anais... São José dos Campos: Inpe, 2005, p. 765-773.

BACKER, L. The geostat project: part of an international effort to build an IISS? In: EUROPEAN FORUM FOR GEOSTATISTICS WORKSHOP, 2008, Bled, Slovenia. Anais... 2008.

BENATTI, J. Unidades de conservação e as populações tradicionais: uma análise jurídica da realidade brasileira. Novos Cadernos NAEA, Pará, v. 2, n. 2, dez. 1999. 
BRASIL. Decreto Lei n. 161, de 13 de fevereiro de 1967. Autoriza o Poder Executivo a instituir a Fundação Instituto Brasileiro de Geografia e Estatística e dá outras providências. Brasília, 1967.

Lei n. 5.534, de 14 de novembro de 1968. Dispõe sobre a obrigatoriedade de prestação de informações estatísticas e dá outras providências. Brasília, 1968.

Lei $\mathbf{n}^{\mathbf{0}}$ 9.985, de 18 de julho de 2000. Institui o Sistema Nacional de Unidades de Conservação da Natureza do Brasil (SNUC). Brasília, 2000.

Decreto no 4.340, de 22 de agosto de 2002. Regulamenta artigos da Lei n. 9.985, de 18 de julho de 2000, que dispõe sobre o Sistema Nacional de Unidades de Conservação da Natureza SNUC, e dá outras providências. Brasília, 2002.

Decreto no 6.040, de 7 de fevereiro de 2007. Institui a Política Nacional de Desenvolvimento Sustentável dos Povos e Comunidades Tradicionais. Brasília, 2007.

Conama - Conselho Nacional do Meio Ambiente. Resolução n. 013, de 06/12/1990. Dispõe sobre a área circundante, num raio de 10 (dez) quilômetros, das Unidades de Conservação. Brasília, 1990.

Conama - Conselho Nacional do Meio Ambiente. Resolução n. 428, de 17/12/2010. Dispõe, no âmbito do licenciamento ambiental sobre a autorização do órgão responsável pela administração da Unidade de Conservação (UC), de que trata o § 30 do artigo 36 da Lei n. 9.985 de 18 de julho de 2000, bem como sobre a ciência do órgão responsável pela administração da UC no caso de licenciamento ambiental de empreendimentos não sujeitos a EIA-RIMA e dá outras providências. Brasília, 2010.

Ministério do Meio Ambiente. Cadastro Nacional de Unidades de Conservação. S.d. Disponivel em: 〈http://www.mma.gov.br/sitio/index.php?ido=conteudo.monta\&idEstrutura=119〉. Acesso em: 20 dez. 2011.

BUENO, M. C. D.; DAGNINO, R. População em unidades de conservação da Amazônia Legal: estimativas a partir da Contagem Populacional 2007. In: D’ANTONA, A. O.; CARMO, R. L. (Orgs.). Dinâmicas demográficas e ambiente. Campinas: Nepo/Unicamp, 2011, p. 85-103.

CARNEIRO DA CUNHA, M.; ALMEIDA, M. Populações tradicionais e conservação ambiental. In: CARNEIRO DA CUNHA, M. Cultura com aspas. Cosac Naify, 2009, p. 277-300.

COELHO, M.; CUNHA, L.; MONTEIRO, M. Unidades de conservação: populações, recursos e territórios. Abordagens da geografia e da ecologia política. In: GUERRA, A.; COELHO, M. (Orgs.). Unidades de conservação: abordagens e características geográficas. Rio de Janeiro: Bertrand Brasil, 2009.

D’ANTONA, A. O. Garantir a terra, garantia da Terra? Reservas Extrativistas na Amazônia Legal Brasileira. Tese (Doutorado em Ciências Sociais), Universidade Estadual de Campinas, Campinas, 2003.

D’ANTONA, A. O.; BUENO, M. C. D.; DAGNINO, R. Using regular grids for spatial distribution of census data for population and environment studies in Brazil. In: POPULATION ASSOCIATION OF AMERICA ANNUAL MEETING PROGRAM, 2011, Washington. Anais...Washington: PAA, 2011.

DE SHERBININ, A. et al. A CIESIN thematic guide to social science applications of remote sensing. New York: Center for International Earth Science Information Network (CIESIN) of Columbia University, 2002.

DEICHMANN, U.; BALK, D.; YETMAN, G. Transforming population data for interdisciplinary usages: from census to grid. Documentação do Grid Population of the Word - GPW, versão 2, 2001. Disponível em: 〈http://sedac.ciesin.columbia.edu/plue/gpw/GPW documentation.pdf〉. Acesso em: abr. 2010.

ESPON - European Spatial Planning Observation Network. The modifiable areas unit problem. Final Report. Luxembourg, 2006. 
GALLEGO, F. J. A population density grid of the European Union. Population and Environment, New York, v. 31, n. 6, 2010.

A downscaled population density map of the EU from commune data and land cover information. In: PROCEEDINGS OFTHE NEW TECHNIQUES AND TECHNOLOGIES FOR STATISTICSSEMINAR NTTS, 2009, Belgium. Anais... 2009.

GISBERT, F. J. G.; MARTI, I. C. Cartografía y demografía: una grid de población para la Comunitat Valenciana. Estadistica Espanola, v. 53, n. 176, 2011.

GOODCHILD, M. F.; ANSELIN, L.; DEICHMANN, U. A Framework for the Areal Interpolation of Socioeconomic Data. Environment and Planning A, v. 25, p. 383-397, 1993.

HOGAN, D. ..; D’ANTONA, A. O.; CARMO, R. L. Dinâmica demográfica recente da Amazônia. In: BATISTELA, M.; MORAN, E.; ALVES, D. (Orgs.). Amazônia: natureza e sociedade em transformação. São Paulo: Edusp, 2008.

IBGE. Geoestatísticas de Recursos Naturais da Amazônia Legal. Estudos e Pesquisas - Informação Geográfica, Rio de Janeiro, n. 8, 2003 [reeditado em formato digital em 2011]. Disponível em: 〈http:// www.ibge.gov.br/home/geociencias/recursosnaturais/diagnosticos_levantamentos/amazonia_legal/ amazonia_legal.pdf>. Acesso em: 15 jul. 2011.

Contagem da População 2007 - Agregado por setores censitários, Documentação do Arquivo. Rio de Janeiro, 2008a.

Censos 2007: inovações e impactos nos sistemas de informações estatísticas e geográficas do Brasil. Rio de Janeiro, 2008b.

Censo Demográfico 2010: os primeiros passos. Rio de Janeiro, 2009.

Janeiro, 2010 .

Base Cartográfica Contínua do Brasil, ao Milionésimo - BCIM. Versão 3.04. Rio de

Censo 2010 - Sinopse do Censo Demográfico 2010. Rio de Janeiro, 2011.

KAMPEL, S. A. Geoinformação para estudos demográficos: representação espacial de dados de população na Amazônia Brasileira. Tese (Doutorado) - Departamento de Engenharia de Transportes, Escola Politécnica da Universidade de São Paulo, São Paulo, 2004.

LANDIM, P. M. B. Introdução aos métodos de estimação espacial para confecção de mapas. DGA, IGCE, Unesp/Rio Claro, Lab. Geomatemática, 2000 (Texto didático, 02).

LANGFORD, M.; UNWIN, D. J. Generating and mapping population density surfaces within a Geographical Information System. The Cartographic Journal, v. 31, p. 21-26, 1995.

MARTIN, D. Mapping population data from zone centroid locations. Transactions of the Institute of British Geographers, v. 8, n. 14, p. 90-97, 1989.

An assessment of surface and zonal models of population. International Journal of Geographical Information Systems, v. 10, p. 973-989, 1996.

MARTIN, D.; TATE, N. J.; LANGFORD, M. Refining population surface models: experiments with Northern Ireland Census Data. Transactions in GIS, v. 4, p. 343-360, 2000.

MENNIS, J. Generating surface models of population using dasymetric mapping. The Professional Geographer, v. 55, n. 1, p. 31-42, 2003.

. Using geographic information systems to create and analyze statistical surfaces of population and risk for environmental justice analysis. Social Science Quarterly, v. 83, n. 1, p. 281-297, 2002.

MENNIS, J.; HULTGREN, T. Intelligent dasymetric mapping and its application to areal interpolation. Cartography and Geographic Information Science, v. 33, n. 3, p. 179-194, 2006 a. 
. Intelligent dasymetric mapping and its comparison with other areal interpolation techniques. In: PROCEEDINGS OF AUTOCARTO 2006, Vancouver. Anais... 2006b.

MILEGO, R.; RAMOS, M. J. Disaggregation of socioeconomic data into a regular grid: results of the methodology testing phase. In: ESPON DATABASE 2013, UAB, 2010, Bellaterra, Espanha. Anais... 2010.

OPENSHAW, S.; OPENSHAW, C. Artificial intelligence in geography. Chichester: John Wiley, 1997.

OPENSHAW, S. The modifiable areal unit problem. Norwich: Geo Books, 1984. (Concepts and Techniques in Modern Geography, n. 38).

POZZI, F.; SMALL, C.; YETMAN, G. Modeling the distribution of human population with nighttime satellite imagery and gridded population of the world. Earth Observation Magazine, v. 12, n. 4, p. 24-30, 2003.

REIBEL, M. Geographic information systems and spatial data processing in demography: a review. Population Research and Policy Review, v. 26, n. 5-6, 2007.

STATISTICS FINLAND. Production and dissemination of grid data since the 1970 Census in Finland. In: CONFERENCE OF EUROPEAN STATISTICIANS, 2010. Paris. Anais... Paris, 2010.

STROMGREN M.; HOLM, E. Using downscaled population in local data generation: a country-level examination. ESPON Technical Report. 2010.

TAMMISTO, R. Merging national population grids (bottom-up approach) into a European dataset. In: GIS FOR STATISTICS, 2007, Luxembourg. Anais... Luxembourg, 2007.

TOBLER, W. R. Linear operators applied to areal data. In: DAVIS, J. C.; McCULLAGH, M. J. (Eds.). Display and analysis of areal data. London: Wiley, 1975, p. 14-38.

Smooth pychnophylactic interpolation for geographical regions. Journal of the American Statistical Association, v. 74, n. 367, p 519-530, 1979.

THURSTAIN-GOODWIN, M.; UNWIN, D. Defining and delineating the central areas of towns for statistical monitoring using continuous surface representations. Transactions in GIS, v. 4, p. 305-17, 2000.

UNITED NATIONS. Handbook on geospatial infrastructure in support of census activities. New York, 2009. (Studies in Methods, Series F, n. 103).

Handbook on geographic information systems and digital mapping. New York, 2000. (Studies in Methods, Series F, n. 79).

WEST, P. C.; BRECHIN, S. R. (Eds.). Resident peoples and national parks: social dilemmas and strategies in international conservation. Tucson: The University of Arizona Press, 1991.

YOO, E.; KYRIAKIDIS, P. C.; TOBLER, W. Reconstructing population density surfaces from areal data: a comparison of tobler's pycnophylactic interpolation method and area-to-point kriging. Geographical Analysis, v. 42, p. 78-98, 2010.

\section{Autores}

Álvaro de Oliveira D’Antona é professor doutor da Faculdade de Ciências Aplicadas (FCA) da Universidade Estadual de Campinas (Unicamp), professor do Programa de Pós-Graduação em Demografia do Instituto de Filosofia e Ciências Humanas (IFCH-Unicamp) e pesquisador colaborador do Núcleo de Estudos de População (Nepo-Unicamp).

Maria do Carmos Dias Bueno é doutoranda do Programa de Pós-Graduação em Demografia do Instituto de Filosofia e Ciências Humanas (IFCH) da Universidade Estadual de Campinas (Unicamp). Tecnologista do Instituto Brasileiro de Geografia e Estatística (IBGE). 
Ricardo de Sampaio Dagnino é doutorando do Programa de Pós-Graduação em Demografia do Instituto de Filosofia e Ciências Humanas (IFCH) da Universidade Estadual de Campinas (Unicamp) e mestre em Geografia.

\section{Abstract \\ Population estimates in conservation units in the Brazilian Legal Amazon - an application of regular grids using the 2007 Population Count}

In this paper a method for increasing the resolution of census data is tested and presented, by aggregating the data onto a regular grid. The methodology consists of (1) the aggregation of households, represented by their geographical coordinates obtained by the 2007 Population Count, carried out by the Brazilian Census Office (IBGE) and, (2) the unbundling of the data by census tracts on the basis of proportionality. The grids obtained were used to estimate the resident population of 114 conservation units in Brazilian Legal Amazon, all of them instituted in or before 2006. The intention was to test this methodology on territorial units that follow neither the official political-administrative boundaries of states and cities, nor the boundaries designed by IBGE for collecting data. The methodology also contributes to the study of populations living in protected areas, due to the scarcity of population estimates in the conservation units. The results showed a population of 325,398 inhabitants in the selected units, 297,693 of whom were in units for Sustainable Use and 27,705 in Permanent Protection units. Adjoining areas have an estimated joint population of 1,020,237. Despite the limitations involved in using the 2007 Population Count, the aggregating of data into grids would seem to be a promising methodology in view of the improvements in IBGE's use of geotechnology. The grid minimizes problems that come up in the use of administrative units or census data and may represent an approach that can be applied usefully in demography and other areas of knowledge.

Keywords: Regular grids. Brazilian Legal Amazon. Conservation Units. Population Estimates.

\section{Resumen}

\section{Estimación de la población en unidades de conservación en la Amazonia Legal brasileña- una aplicación de mallas regulares a partir del Conteo 2007}

En el presente artículo se prueba un método para aumentar la resolución de datos censitarios y presentarlos agregados en una malla regular. La metodología que se utiliza se compone de la agregación de las viviendas representadas por sus coordinadas geográficas obtenidas por el Conteo de la Población del Instituto Brasileiro de Geografia e Estatística (IBGE) de 2007 y la desagregación de los datos por sector censitario utilizando proporcionalidad de área. Los datos generados de este modo fueron utilizados para estimar la población residente en 114 unidades de conservación de la Amazonia Legal brasileña, creadas hasta el 2006, a fin de probar la metodología en unidades territoriales que no siguen los límites político-administrativos ni tampoco los de las unidades territoriales de encuesta utilizados por el IBGE. Dicha metodología también contribuye para los estudios de población en áreas protegidas, dada la escasez de estimaciones del volumen de la población en unidades de conservación. Los resultados mostraron una población en las unidades seleccionadas de 325.398 habitantes, siendo 297.693 en unidades de Uso Sostenible y 27.705 en unidades de Protección Integral; en el entorno se estimó una población de 1.020.237 habitantes. A pesar de limitaciones inherentes al uso del Conteo 2007, la agregación de datos en mallas se revela como una metodología bastante promisoria, teniendo 
en cuenta los avances en el empleo de las geotecnologías por parte del IBGE desde entonces. La malla minimiza problemas observados en el uso de unidades administrativas o de recolección de datos para la espacialización de los datos censales y se presenta como un abordaje con gran potencial de aplicación en la Demografía y en otras áreas del saber.

Palabras clave: Mallas regulares. Amazonia Legal brasileña. Unidades de conservación. Estimaciones de población.

Recebido para publicação em 30/03/2012 Aceito para publicação em 21/07/2012 


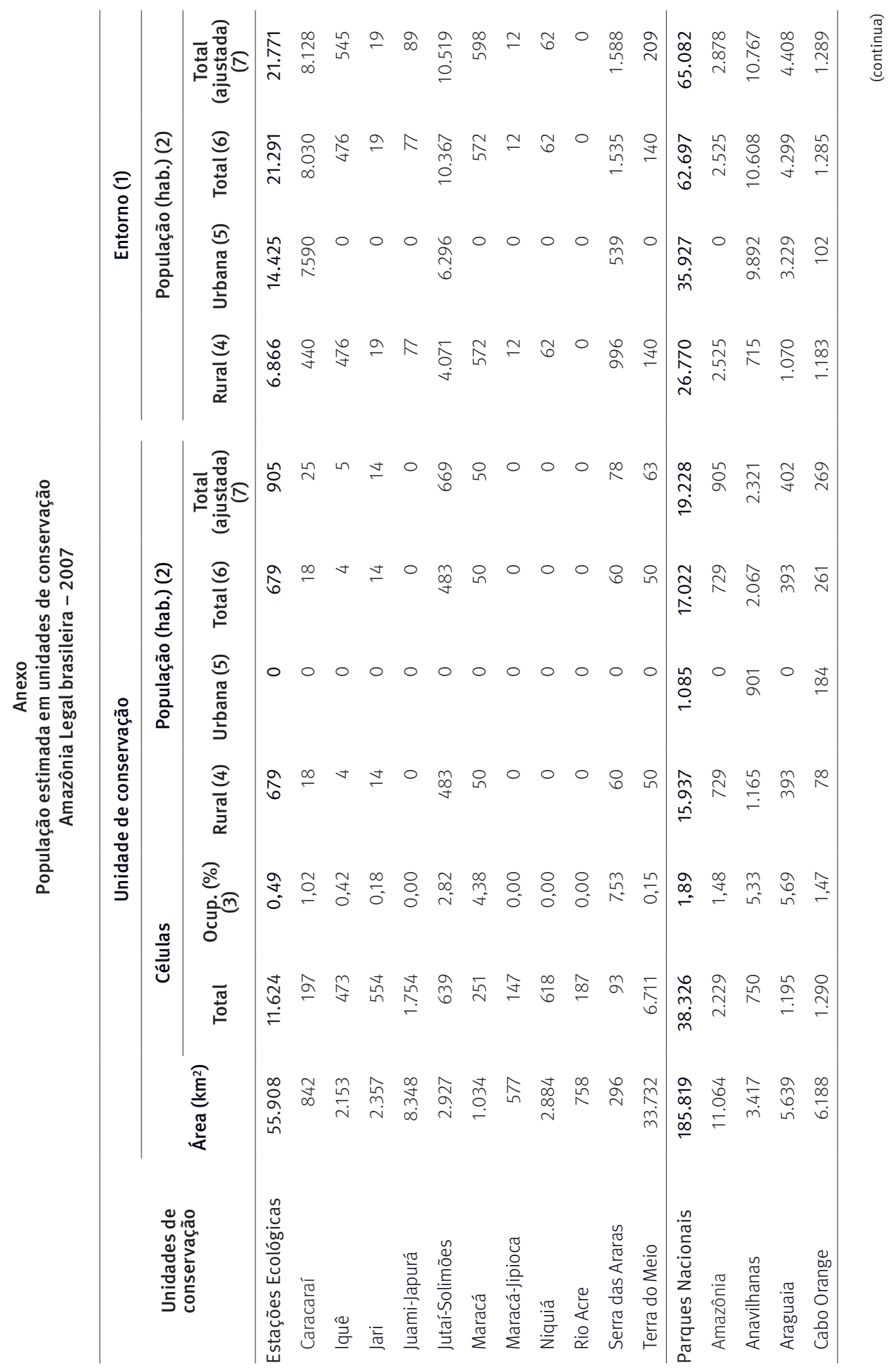




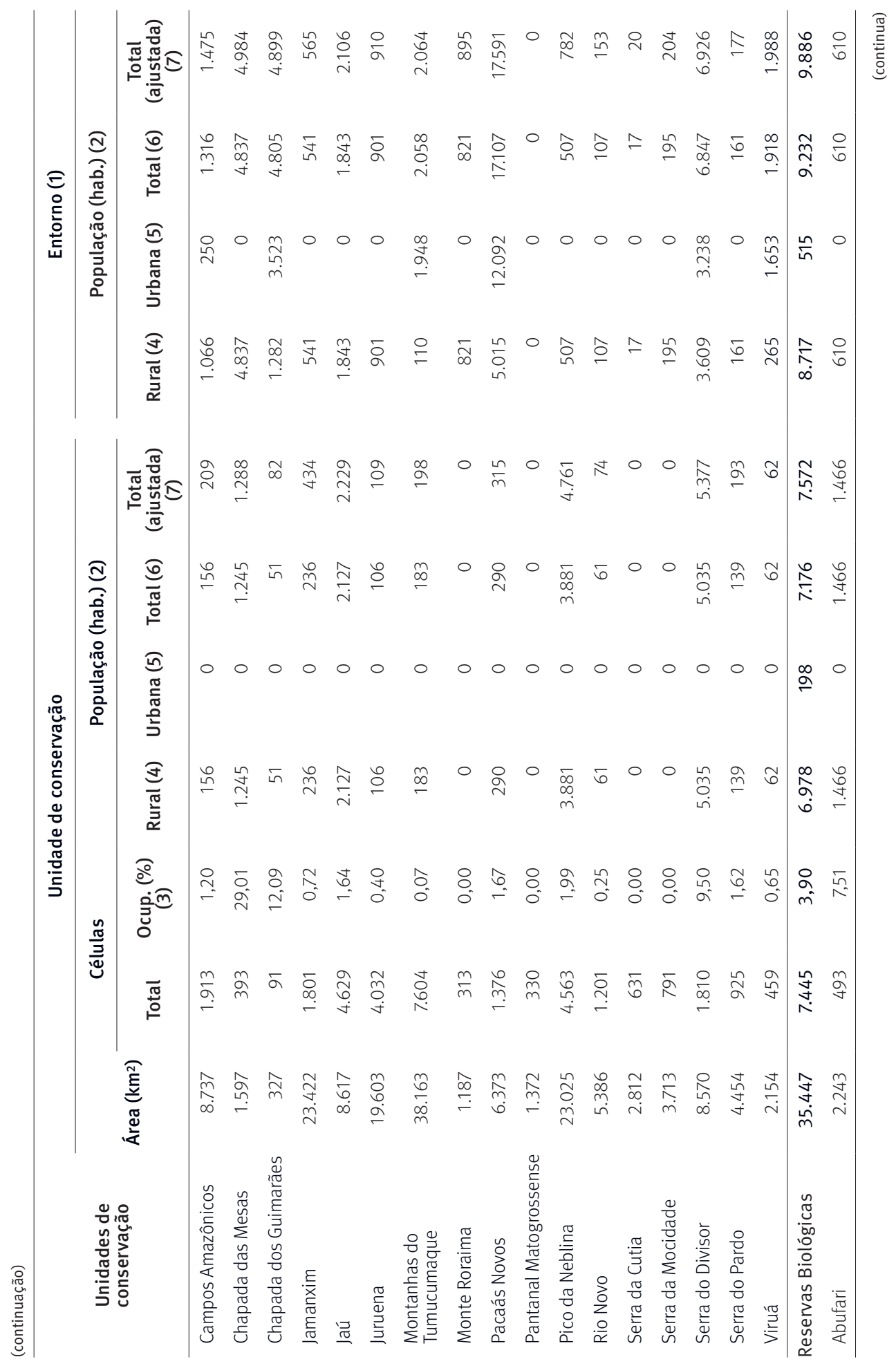




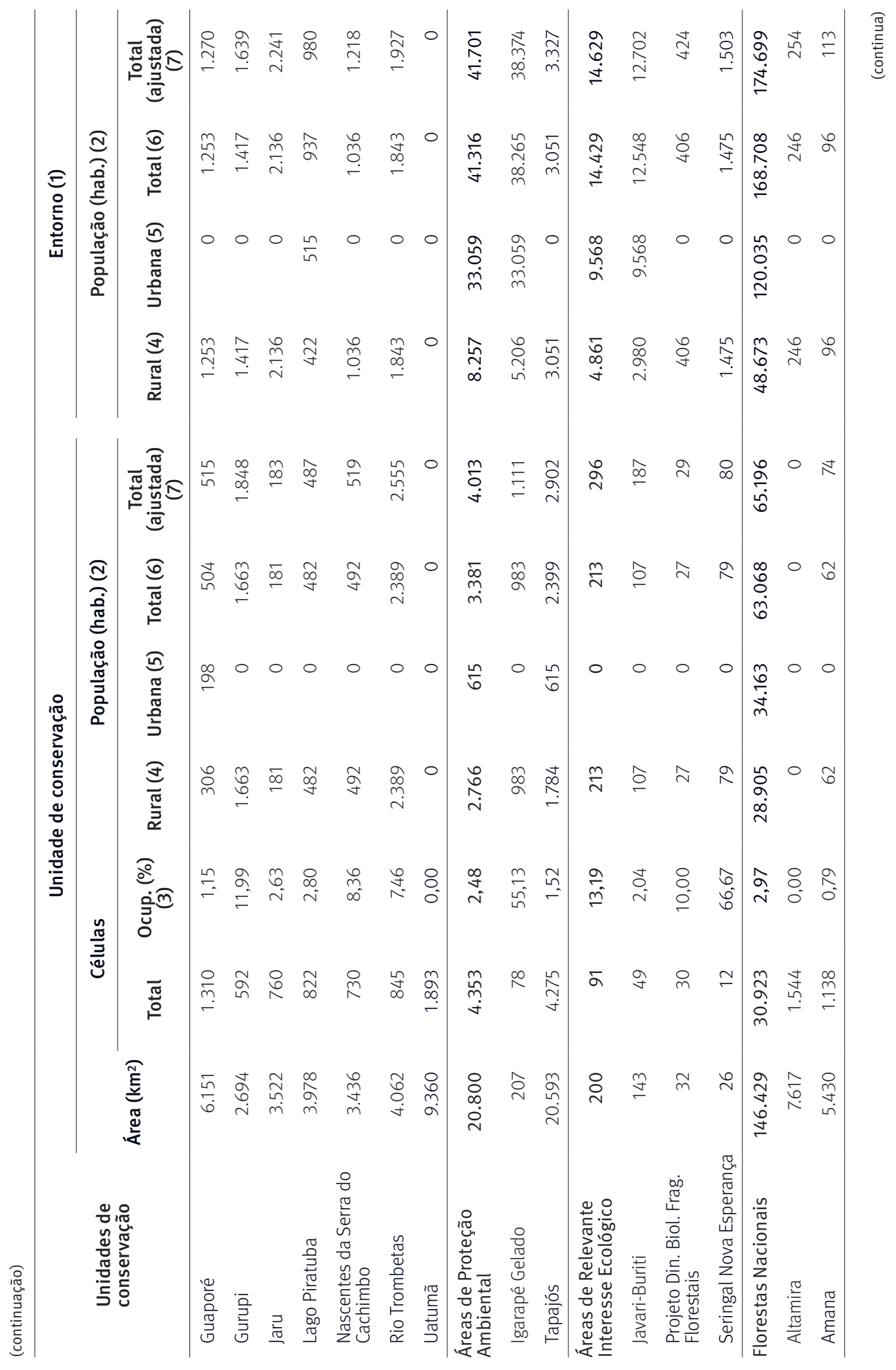




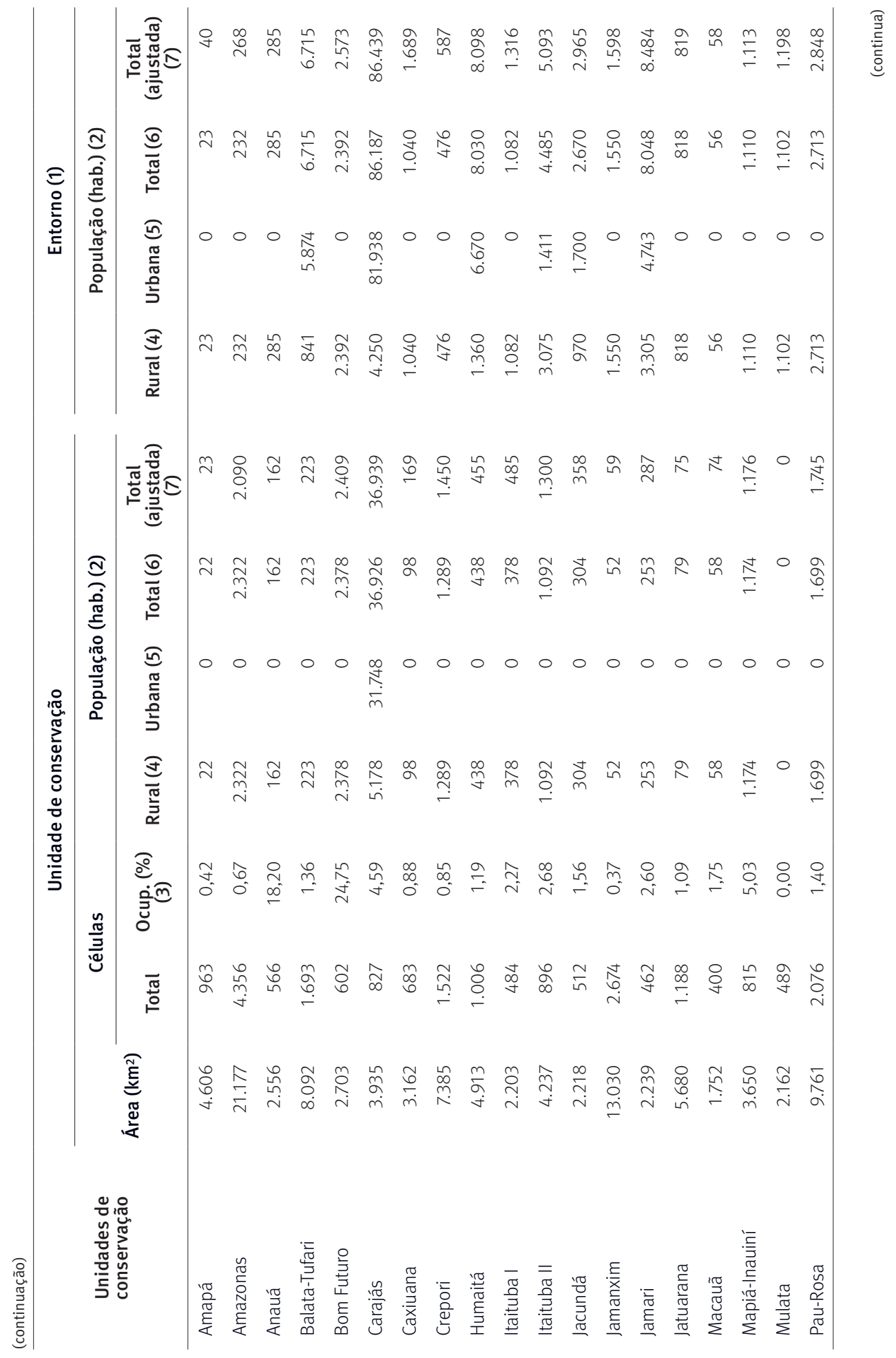




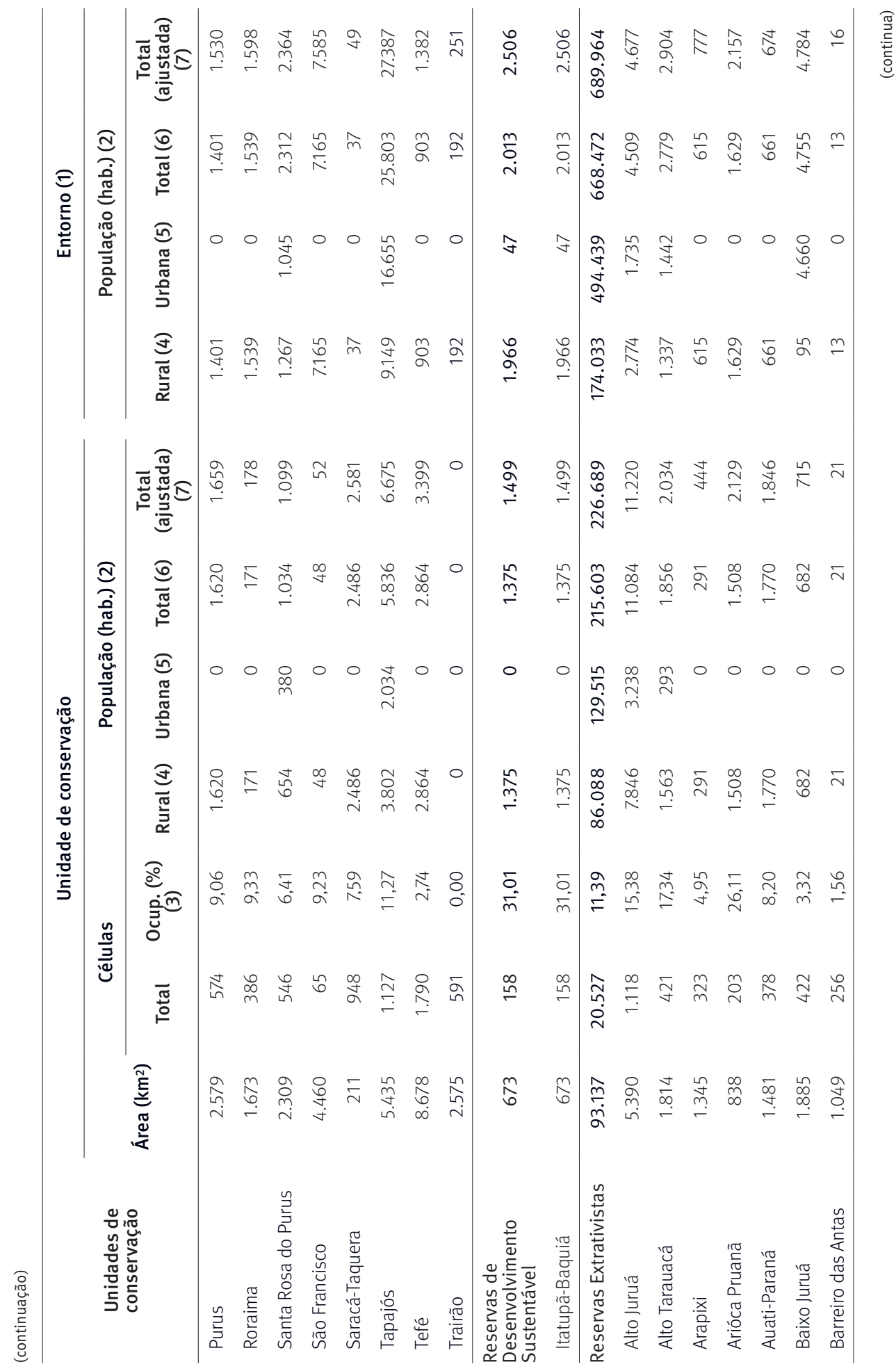




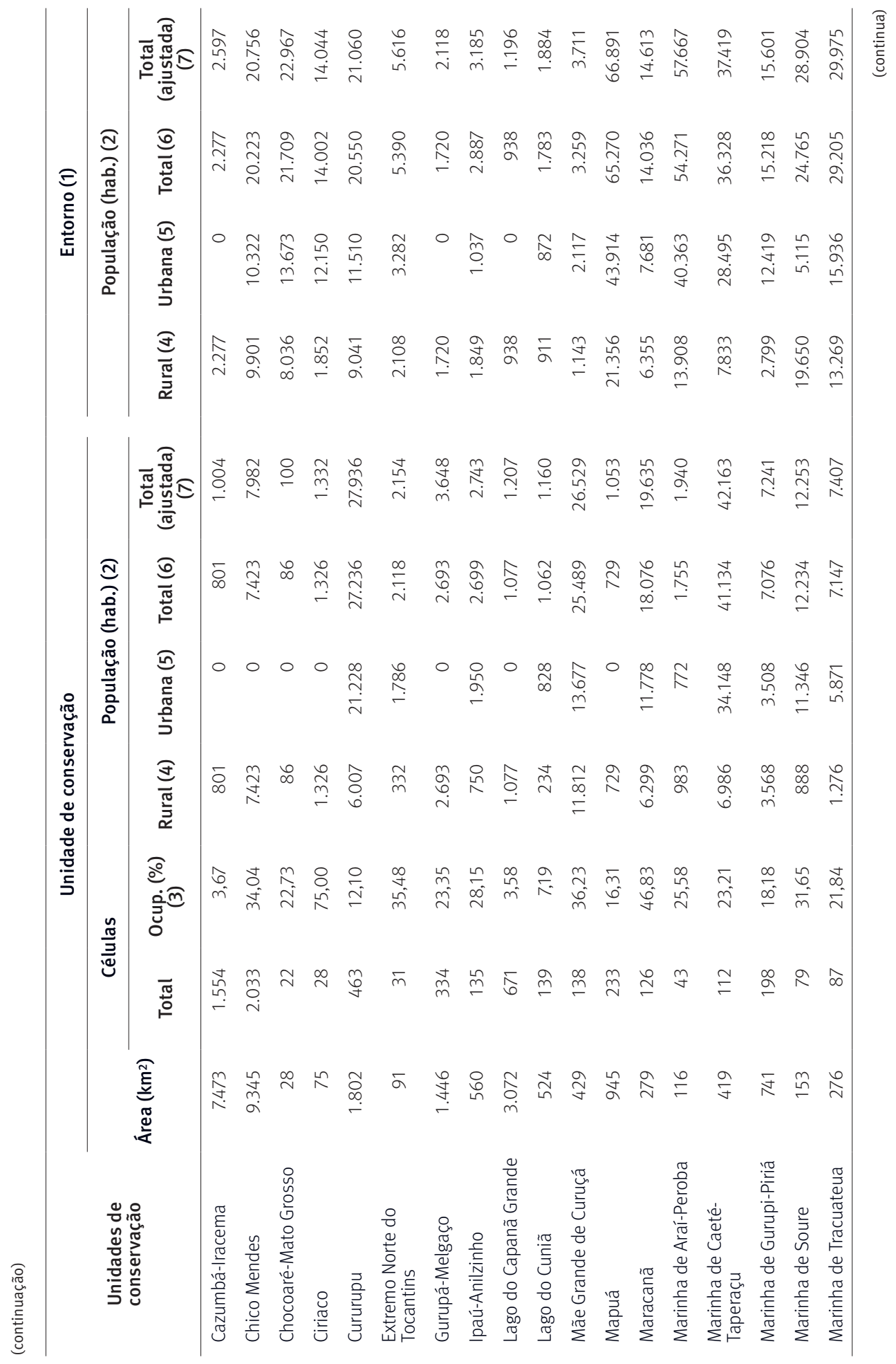




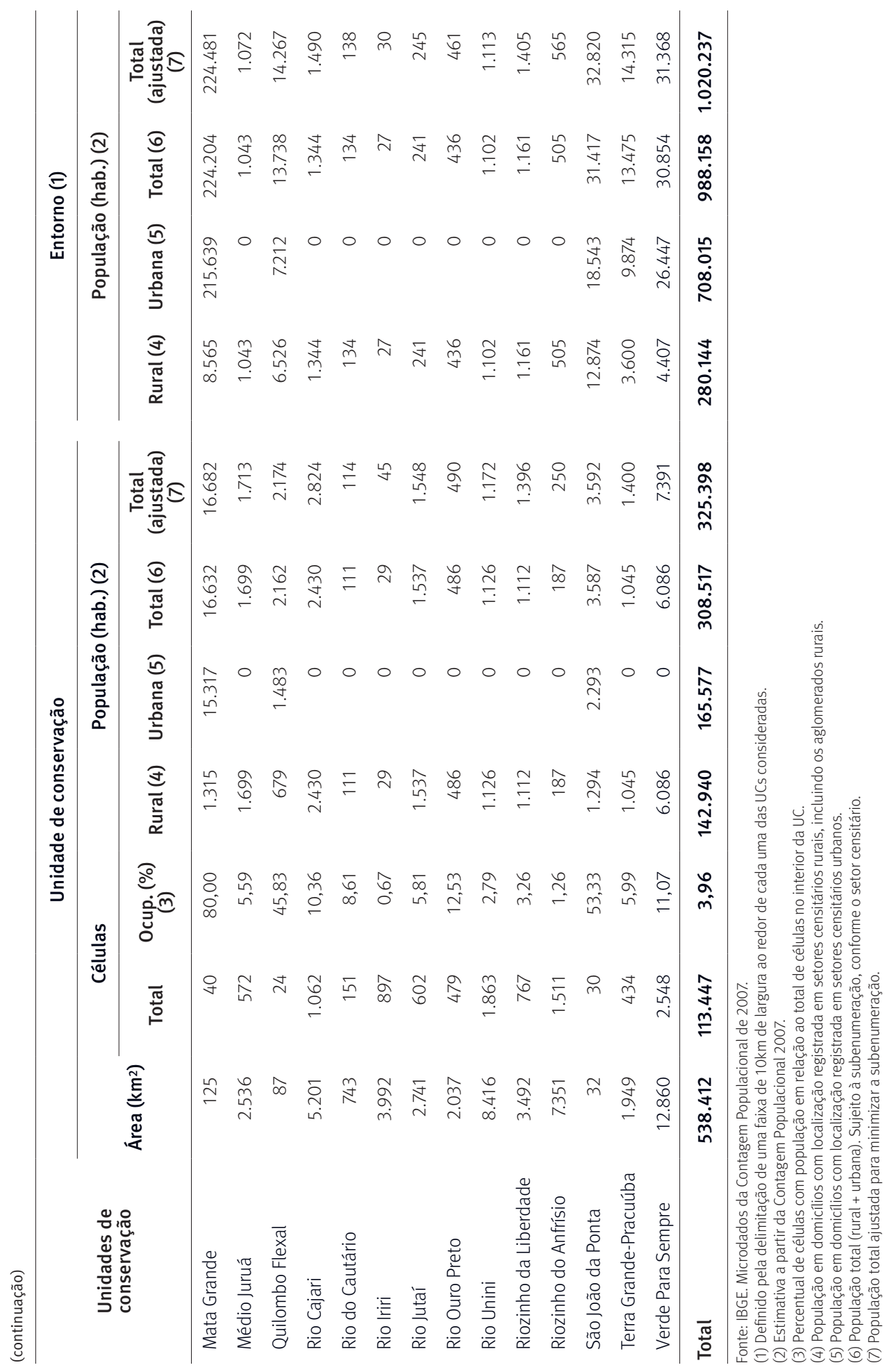

